\title{
The association between interleukin-1 $\beta$ gene polymorphisms and the risk of breast cancer: a systematic review and meta-analysis
}

Bei Wang ${ }^{1,2}$, Fenlai Yuan ${ }^{1,2}$

\author{
1Department of Central Laboratory, The Hospital Affiliated to Jiangnan University, Wuxi, \\ Jiangsu, China \\ ${ }^{2}$ Department of Central Laboratory, The Third Hospital Affiliated to Nantong University, \\ Wuxi, Jiangsu, China
}

Submitted: 28 July 2018; Accepted: 18 November 2018 Online publication: 18 March 2021

Arch Med Sci 2022; 18 (1): 1-10

DOI: https://doi.org/10.5114/aoms/99839

Copyright @ 2021 Termedia \& Banach

\begin{abstract}
Introduction: It is reported that there is a close association between interleukin-1 $\beta$ (IL-1 $\beta$ ) gene polymorphisms and breast cancer risk. However, the results remain controversial.

Material and methods: Eligible published articles were searched in PubMed, Embase, and Web of Science databases up to June 2018. Odds ratios with $95 \%$ confidence intervals were used to identify potential links between IL-1 $\beta$ genetic polymorphisms and the risk of breast cancer.

Results: From our results, we found that three common polymorphisms in IL-1 $\beta$ (rs16944, rs1143634, rs1143627) had no significant associations with breast cancer risk in all genetic models. Based on the analysis from ethnic subgroups, there was a higher risk of breast cancer for rs 16944 polymorphism in the recessive model and heterozygous model among Asians (TT vs. CC+CT: $1.229,95 \% \mathrm{Cl}: 1.063-1.422, p=0.005$; TT vs. CT: 1.211 , $95 \% \mathrm{Cl}: 1.057-1.388, p=0.006)$. For the rs 1143627 polymorphism, a significantly decreased breast cancer risk was observed in the dominant model only in Asians (CT+TT vs. CC: OR $=0.944,95 \% \mathrm{Cl}: 0.897-0.994, p=0.027)$. After stratifying patients according to the menopausal state, we found that polymorphism of rs 1143627 correlated with reduced breast cancer risk among post-menopausal women in three genotype models: allele, recessive model and homozygous model ( $\mathrm{T}$ vs C: $0.859,95 \% \mathrm{Cl}$ : $0.753-0.98, p=0.024$; TT vs. CC+CT: $0.727,95 \% \mathrm{Cl}: 0.576-0.918, p=0.007$; TT vs. CC: 0.743 , $95 \% \mathrm{Cl}: 0.626-0.882, p=0.001)$. As for other analyses with reference to source of controls and genotyping methods, no significant association between IL-1 $\beta$ polymorphism and breast cancer risk was demonstrated.

Conclusions: The rs16944 and rs1143627 polymorphisms are significantly associated with the risk of breast cancer only in Asian people and in postmenopausal women respectively.
\end{abstract}

Key words: polymorphism, breast cancer, interleukin-1 $\beta$, meta-analysis.

\section{Introduction}

Breast cancer is a complex multiple process influenced by multiple factors. It is considered that specific gene polymorphisms have effects on gene transcription, mRNA stability and protein activity [1]. Multi-functional cytokines involved in the process of inflammatory and

\author{
Corresponding author: \\ Bei Wang PhD \\ The Hospital Affiliated \\ to Jiangnan University \\ Huihe Road 200 \\ Binghu district \\ 214125 WuXi, China \\ E-mail: \\ xuewuhenwang@126.com
}


immunological responses are closely associated with the pathogenesis of autoimmune and malignant diseases, making them potential risks for breast cancer [2-4]. The interleukin 1 gene family located on chromosome 2q14.2 includes three members: IL- $1 \alpha, I L-1 \beta$ and IL- 1 receptor antagonist (IL-RA) encoded by IL-1RN [5]. Interleukin $1 \alpha$ and IL-1 $\beta$ are potent proinflammatory cytokines, whereas IL-RA is an anti-inflammatory cytokine [6]. Interleukin $1 \beta$ can be produced by various cells and it modifies the process of host response to microbial invasion, tissue injury and inflammation [7].

The interleukin $1 \beta$ gene has three potentially functional SNPs: -31 ( $r$ 1143627, C>T), -511 ( $r s 16944, C>T)$ in the promoter region and +3954 ( $r s 1143634, C>T)$ in exon $5[8,9]$. So far, many studies have been conducted to assess the relations between the three SNPs (rs16944, rs1143634 and $\mathrm{rs} 1143627)$ in IL-1 $\beta$ and breast cancer risk [10-20]. However, the results remain conflicting. Therefore, we performed this meta-analysis in order to obtain a more precise evaluation of these links.

\section{Material and methods}

\section{Literature search}

Relevant studies published before June $1^{\text {st }}$, 2018 were identified through a search in PubMed, Embase, and Web of Science using a combination of the following terms: ("polymorphism" or "SNP" or "single nucleotide polymorphisms"), ("breast cancer" or "breast carcinoma" or "breast tumor") and ("Interleukin-1" or "IL-1 $\beta$ " or "Interleukin-1 beta"). The references from the eligible articles or textbooks were also manually searched by us to find additional potential sources.

\section{Inclusion and exclusion criteria}

The criteria for studies in our meta-analysis are as follows: (a) studies concentrated on relations between IL-1 $\beta$ polymorphisms and breast cancer risk; (b) providing sufficient data for the frequencies of alleles and genotypes; (c) published in English. Studies were excluded when: (a) they were not case-control studies; (b) did not supply complete and essential information; (c) they were meta-analyses, reviews, or editorial articles.

\section{Data extraction}

Data were extracted from each publication independently by two authors (Wang and Yuan) based on the inclusion criteria mentioned above. For each study, the data were collected as follows: the first author, year of publication, country of origin, ethnicity, menopausal state, numbers of pa- tients and controls, source of controls, mutation detection methods, genotyping methods, minor allele frequency (MAF), allele and genotype frequencies and the evidence of Hardy-Weinberg equilibrium (HWE) in controls. Disputes were settled by consulting with a third author if disagreements occured.

\section{Statistical analysis}

In order to assess the strength of associations between IL-1 $\beta$ gene polymorphisms and breast cancer susceptibility under five genetic models which include the allele model, dominant model, recessive model, homozygous model and the heterozygous model, crude odds ratios (ORs) with their corresponding 95\% confidence intervals (Cls) were adopted [21-24]. Hardy-Weinberg equilibrium in control groups was estimated using the $\chi^{2}$ test. The pooled OR's statistical significance was verified using the $Z$ test with a two-tailed $p<0.05$ which is regarded as statistically significant. Between-study variations and heterogeneities were evaluated using either Cochran's Q-statistic or $1^{2}$ test. When the result is a $p$-value $<0.05$ or $l^{2}>50 \%$, it indicates the existence of heterogeneity among studies; only in this circumstance was the random effects model (DerSimonian Laird method) used. If not, the fixed effects model (Mantel-Haenszel method) was performed. In order to explore sources of heterogeneity, we performed subgroup analysis with reference to ethnicity, menopausal state, source of controls and genotyping methods. Additionally, to investigate the sensitivity, we removed each study in turn to evaluate the quality and consistency of results. We used Begg's funnel plot and Egger's linear regression test to detect publication biases. All analyses were conducted with STATA version 12.0.

\section{Results}

\section{Eligible studies}

Four studies with controls deviating from HWE were excluded $[12,15,18,20]$. Ten case-control studies were conducted by us to assess associations between IL-1 $\beta$ polymorphisms and breast cancer risk. As shown in Tables I and II, 6 studies were eligible for $r s 16944(C>T)$ including 2454 cases and 2720 controls [11, 12, 14, 16, 18, 19]. Details are as follows: 1) Caucasians, Asians, and Africans were investigated in 4, 2 and 1 studies respectively, 3 of which were associated with menopause. 2) Only 1 study was based on PB regarding the source of controls. 3) Genotype methods included TaqMan, PCR, sequencing and MALDI-TOF. For rs1143634(C>T), it was the same as above, but only two studies were qualified, which 
Table I. Characteristics of case-control studies included in the meta-analysis

\begin{tabular}{|c|c|c|c|c|c|c|c|c|}
\hline SNPs/First author & Year & $\begin{array}{c}\text { Racial } \\
\text { descent }\end{array}$ & Country & $\begin{array}{l}\text { Menopausal } \\
\text { state }\end{array}$ & $\begin{array}{c}\text { Source } \\
\text { of controls }\end{array}$ & $\begin{array}{l}\text { Genotype } \\
\text { methods }\end{array}$ & Cases & Controls \\
\hline \multicolumn{9}{|l|}{ rs16944: } \\
\hline Smith & 2004 & Caucasian & UK & $\mathrm{N}$ & PB & Taqman & 141 & 261 \\
\hline Hefler & 2005 & Caucasian & Germany & N & $\mathrm{HB}$ & PCR & 269 & 227 \\
\hline Liu & 2006 & Asian & China & N & $\mathrm{HB}$ & PCR & 365 & 631 \\
\hline Balasubramanian & 2006 & Caucasian & UK & $\mathrm{N}$ & $\mathrm{HB}$ & PCR & 703 & 489 \\
\hline Pooja & 2012 & Asian & India & $\begin{array}{c}\text { Pre- } \\
\text { menopausal }\end{array}$ & $\mathrm{HB}$ & Sequence & 107 & 200 \\
\hline Pooja & 2012 & Asian & India & $\begin{array}{c}\text { Post- } \\
\text { menopausal }\end{array}$ & $\mathrm{HB}$ & Sequence & 93 & 200 \\
\hline Gong & 2013 & Caucasian & American & $\begin{array}{c}\text { Pre- } \\
\text { menopausal }\end{array}$ & $\mathrm{HB}$ & MALDL-TOF & 185 & 163 \\
\hline Gong & 2013 & Caucasian & American & $\begin{array}{c}\text { Post- } \\
\text { menopausal }\end{array}$ & $\mathrm{HB}$ & MALDL-TOF & 141 & 146 \\
\hline Gong & 2013 & African & American & $\begin{array}{c}\text { Pre- } \\
\text { menopausal }\end{array}$ & $\mathrm{HB}$ & MALDL-TOF & 237 & 195 \\
\hline Gong & 2013 & African & American & $\begin{array}{c}\text { Post- } \\
\text { menopausal }\end{array}$ & $\mathrm{HB}$ & MALDL-TOF & 213 & 208 \\
\hline Zuo & 2018 & Asian & China & N & $\mathrm{HB}$ & $\begin{array}{l}\text { Sequenom } \\
\text { MassARRAY }\end{array}$ & 530 & 628 \\
\hline \multicolumn{9}{|l|}{ rs1143634: } \\
\hline Snoussi & 2005 & African & Tunisia & $N$ & $\mathrm{HB}$ & PCR & 305 & 200 \\
\hline Hefler & 2005 & Caucasian & Germany & $\mathrm{N}$ & $\mathrm{HB}$ & PCR & 269 & 227 \\
\hline Balasubramanian & 2006 & Caucasian & UK & $\mathrm{N}$ & $\mathrm{HB}$ & PCR & 691 & 420 \\
\hline Pooja & 2012 & Asian & India & $\begin{array}{c}\text { Pre- } \\
\text { menopausal }\end{array}$ & $\mathrm{HB}$ & Sequence & 107 & 200 \\
\hline Pooja & 2012 & Asian & India & $\begin{array}{c}\text { Post- } \\
\text { menopausal }\end{array}$ & $\mathrm{HB}$ & Sequence & 93 & 200 \\
\hline Pooja & 2012 & Asian & India & $\mathrm{N}$ & $\mathrm{HB}$ & Sequence & 200 & 200 \\
\hline \multicolumn{9}{|l|}{ rs1143627: } \\
\hline Ito & 2002 & Asian & Japan & $\mathrm{N}$ & $\mathrm{HB}$ & PCR-CTPP & 227 & 185 \\
\hline Liu & 2006 & Asian & China & N & $\mathrm{HB}$ & PCR & 365 & 631 \\
\hline Lee & 2006 & Asian & Korea & $\begin{array}{c}\text { Pre- } \\
\text { menopausal }\end{array}$ & PB & PCR-CTPP & 353 & 290 \\
\hline Lee & 2006 & Asian & Korea & $\begin{array}{c}\text { Post- } \\
\text { menopausal }\end{array}$ & PB & PCR-CTPP & 206 & 215 \\
\hline Lee & 2006 & Asian & Korea & $\mathrm{N}$ & PB & PCR-CTPP & 559 & 505 \\
\hline Akisik & 2007 & Asian & Turkey & $\mathrm{N}$ & $\mathrm{N}$ & PCR-RFLP & 126 & 110 \\
\hline Gong & 2013 & Caucasian & American & $\begin{array}{c}\text { Pre- } \\
\text { menopausal }\end{array}$ & $\mathrm{HB}$ & MALDL-TOF & 186 & 166 \\
\hline Gong & 2013 & Caucasian & American & $\begin{array}{c}\text { Post- } \\
\text { menopausal }\end{array}$ & $\mathrm{HB}$ & MALDL-TOF & 142 & 146 \\
\hline Gong & 2013 & African & American & $\begin{array}{c}\text { Pre- } \\
\text { menopausal }\end{array}$ & $\mathrm{HB}$ & MALDL-TOF & 239 & 195 \\
\hline Gong & 2013 & African & American & $\begin{array}{c}\text { Post- } \\
\text { menopausal }\end{array}$ & $\mathrm{HB}$ & MALDL-TOF & 216 & 210 \\
\hline Zuo & 2018 & Asian & China & $\mathrm{N}$ & $\mathrm{HB}$ & $\begin{array}{l}\text { Sequenom } \\
\text { MassARRAY }\end{array}$ & 530 & 628 \\
\hline
\end{tabular}


Bei Wang, Fenlai Yuan

Table II. Characteristics of case-control studies included in the meta-analysis

\begin{tabular}{|c|c|c|c|c|c|c|c|c|c|c|c|c|c|}
\hline \multirow[t]{3}{*}{ SNPs/First author } & \multicolumn{12}{|c|}{ Genetype distribution } & \multirow[t]{3}{*}{ HWE test } \\
\hline & \multicolumn{6}{|c|}{ Cases } & \multicolumn{6}{|c|}{ Controls } & \\
\hline & $\mathrm{C}$ & $\mathrm{T}$ & $\mathrm{CC}$ & $\mathrm{CT}$ & TT & MAF & $\mathrm{C}$ & $\mathrm{T}$ & $\mathrm{CC}$ & $\mathrm{CT}$ & $\mathrm{TT}$ & MAF & \\
\hline \multicolumn{14}{|l|}{ rs16944: } \\
\hline Smith & 187 & 95 & 60 & 67 & 14 & 0.34 & 309 & 213 & 87 & 135 & 39 & 0.41 & 0.25 \\
\hline Hefler & 362 & 176 & 124 & 114 & 31 & 0.33 & 287 & 167 & 88 & 111 & 28 & 0.37 & 0.61 \\
\hline Liu & 358 & 372 & 94 & 170 & 101 & 0.49 & 699 & 563 & 197 & 305 & 129 & 0.45 & 0.58 \\
\hline Balasubramanian & 972 & 434 & 339 & 294 & 70 & 0.31 & 670 & 308 & 232 & 206 & 51 & 0.31 & 0.61 \\
\hline Pooja & 67 & 147 & 12 & 43 & 52 & 0.31 & 144 & 256 & 25 & 94 & 81 & 0.36 & 0.78 \\
\hline Pooja & 70 & 116 & 18 & 34 & 41 & 0.38 & 144 & 256 & 25 & 94 & 81 & 0.36 & 0.78 \\
\hline Gong & 254 & 116 & 88 & 78 & 19 & 0.31 & 215 & 111 & 72 & 71 & 20 & 0.34 & 0.71 \\
\hline Gong & 160 & 122 & 49 & 62 & 30 & 0.22 & 205 & 87 & 71 & 63 & 12 & 0.29 & 0.71 \\
\hline Gong & 221 & 253 & 56 & 109 & 72 & 0.47 & 178 & 212 & 44 & 90 & 61 & 0.46 & 0.33 \\
\hline Gong & 188 & 238 & 34 & 120 & 59 & 0.44 & 193 & 223 & 49 & 95 & 64 & 0.46 & 0.24 \\
\hline Zuo & 556 & 504 & 160 & 236 & 134 & 0.48 & 628 & 628 & 142 & 344 & 142 & 0.5 & 0.02 \\
\hline \multicolumn{14}{|l|}{ rs1143634: } \\
\hline Snoussi & 428 & 182 & 157 & 114 & 34 & 0.29 & 306 & 94 & 120 & 66 & 14 & 0.24 & 0.24 \\
\hline Hefler & 415 & 123 & 159 & 97 & 13 & 0.23 & 337 & 117 & 119 & 99 & 9 & 0.26 & 0.04 \\
\hline Balasubramanian & 1062 & 320 & 410 & 242 & 39 & 0.23 & 629 & 211 & 231 & 167 & 22 & 0.25 & 0.24 \\
\hline Pooja & 178 & 36 & 75 & 28 & 4 & 0.17 & 364 & 36 & 176 & 12 & 12 & 0.09 & $<0.01$ \\
\hline Pooja & 160 & 26 & 76 & 18 & 4 & 0.13 & 364 & 36 & 176 & 12 & 12 & 0.09 & $<0.01$ \\
\hline Pooja & 340 & 60 & 147 & 46 & 7 & 0.15 & 364 & 36 & 176 & 12 & 12 & 0.09 & $<0.01$ \\
\hline \multicolumn{14}{|l|}{ rs1143627: } \\
\hline Ito & 219 & 235 & 58 & 103 & 66 & 0.48 & 155 & 215 & 28 & 99 & 58 & 0.42 & 0.18 \\
\hline Liu & 379 & 351 & 102 & 175 & 88 & 0.48 & 579 & 683 & 133 & 313 & 185 & 0.46 & 0.98 \\
\hline Lee & 344 & 362 & 96 & 152 & 105 & 0.49 & 285 & 295 & 70 & 145 & 75 & 0.49 & 0.99 \\
\hline Lee & 209 & 203 & 51 & 107 & 48 & 0.58 & 211 & 219 & 43 & 125 & 47 & 0.49 & 0.02 \\
\hline Lee & 553 & 565 & 147 & 259 & 153 & 0.49 & 496 & 514 & 113 & 270 & 122 & 0.49 & 0.12 \\
\hline Akisik & 99 & 153 & 18 & 63 & 45 & 0.29 & 98 & 122 & 21 & 56 & 33 & 0.45 & 0.75 \\
\hline Gong & 119 & 253 & 20 & 79 & 87 & 0.32 & 113 & 219 & 21 & 71 & 74 & 0.34 & 0.54 \\
\hline Gong & 122 & 162 & 30 & 62 & 50 & 0.43 & 87 & 205 & 12 & 63 & 71 & 0.29 & 0.71 \\
\hline Gong & 282 & 196 & 84 & 114 & 41 & 0.41 & 238 & 152 & 76 & 86 & 33 & 0.39 & 0.31 \\
\hline Gong & 266 & 166 & 81 & 104 & 31 & 0.38 & 246 & 174 & 77 & 92 & 41 & 0.41 & 0.16 \\
\hline Zuo & 510 & 550 & 136 & 238 & 156 & 0.48 & 630 & 626 & 144 & 342 & 142 & 0.49 & 0.03 \\
\hline
\end{tabular}

contained 996 cases and 620 controls [13, 14]. Finaly, for rs1143627(C>T), just 2413 cases and 2438 controls were involved in five studies [10, 15-17, 19]. Genotype distributions in controls of all studies were in accordance with HWE.

\section{Meta-analysis}

The critical results of the current meta-analysis are described in Table III. Based on data, three common polymorphisms in IL-1 1 (rs16944, rs1143634, rs1143627) were not significantly 


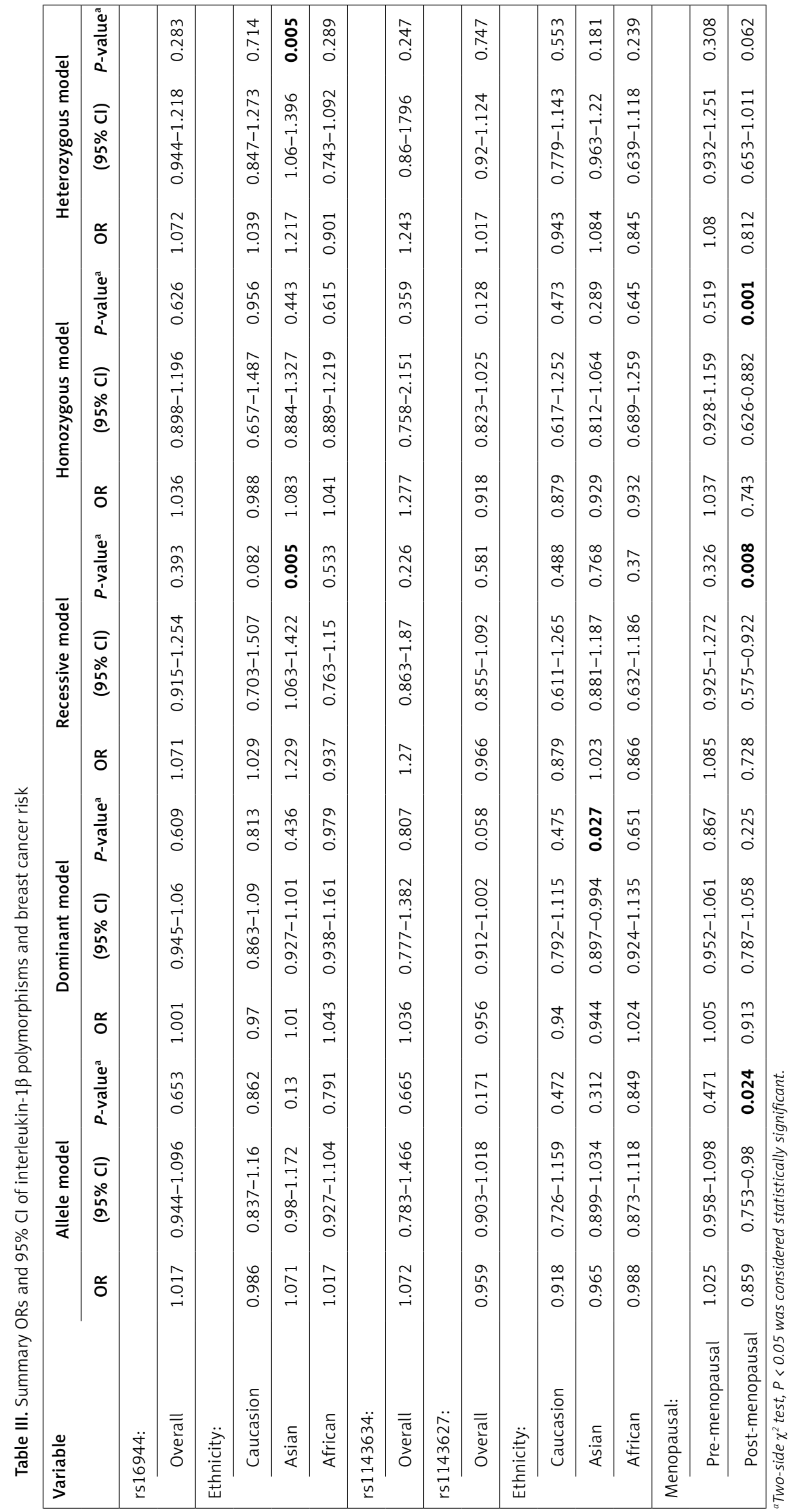




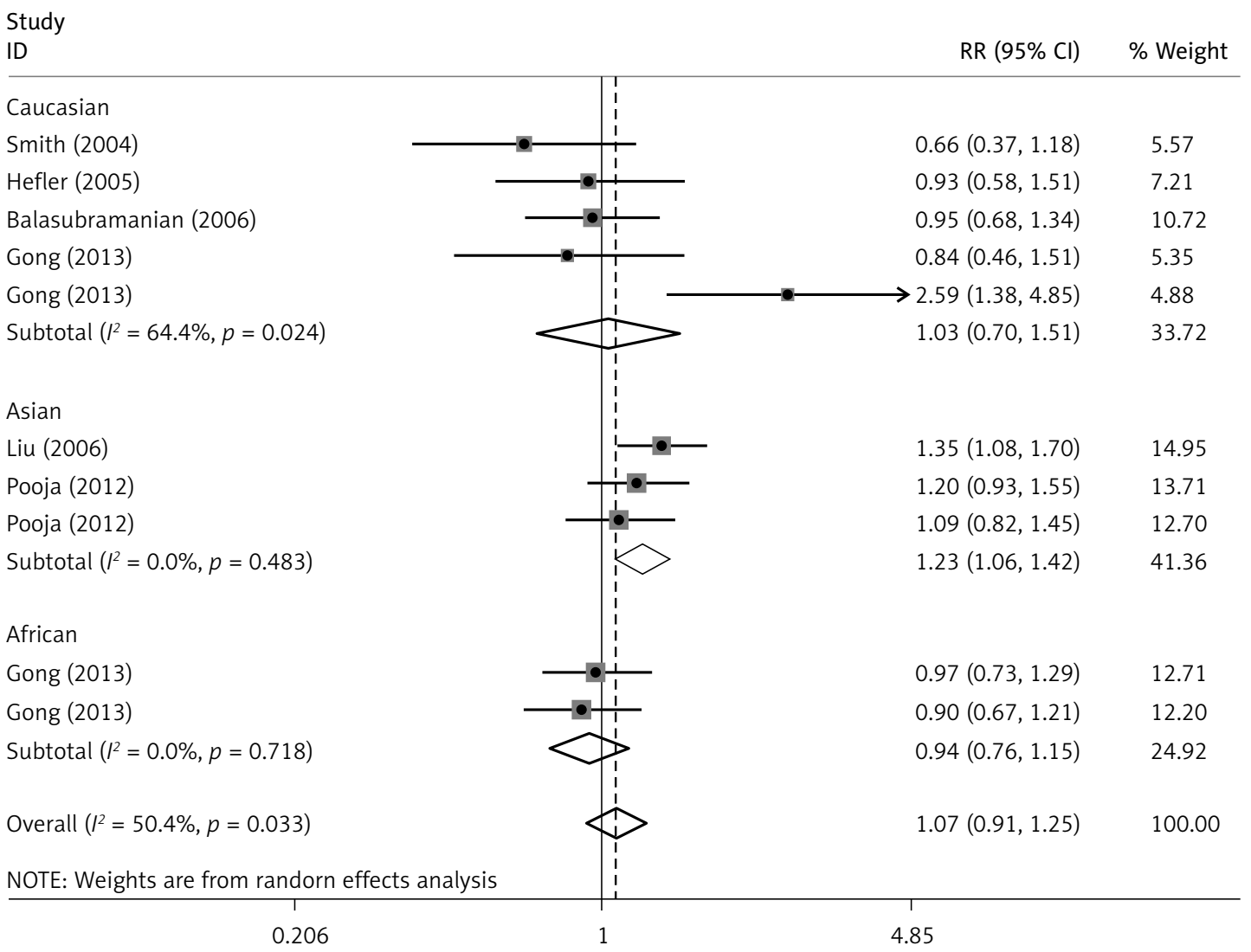

Figure 1. OR of breast cancer in different ethnicities associated with rs16944 in IL-1 $\beta$ gene for the TT genotype compared with the CC + CT genotype

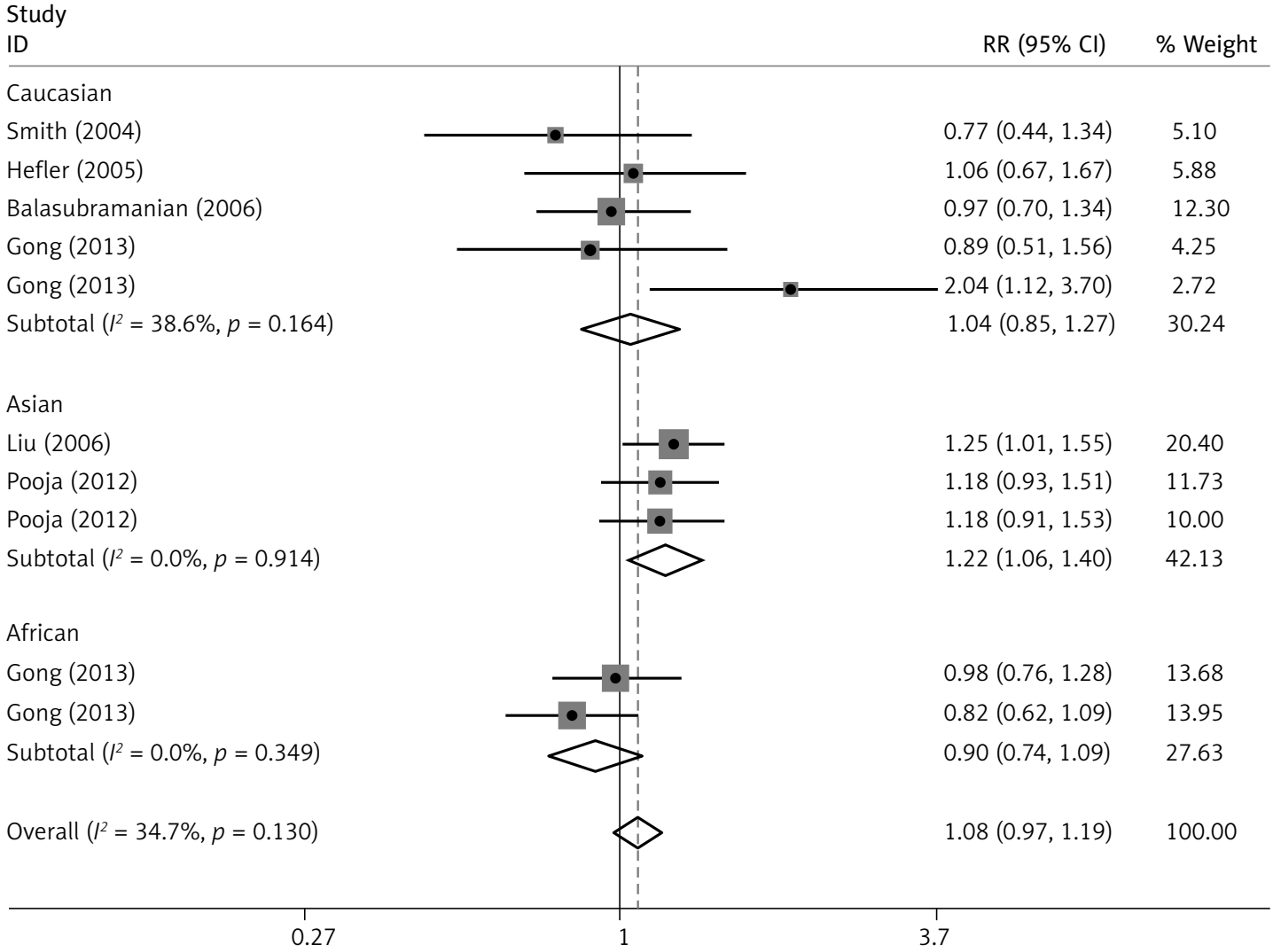

Figure 2. OR of breast cancer in different ethnicities associated with rs16944 in IL-1 $\beta$ gene for the TT genotype compared with the CT genotype 


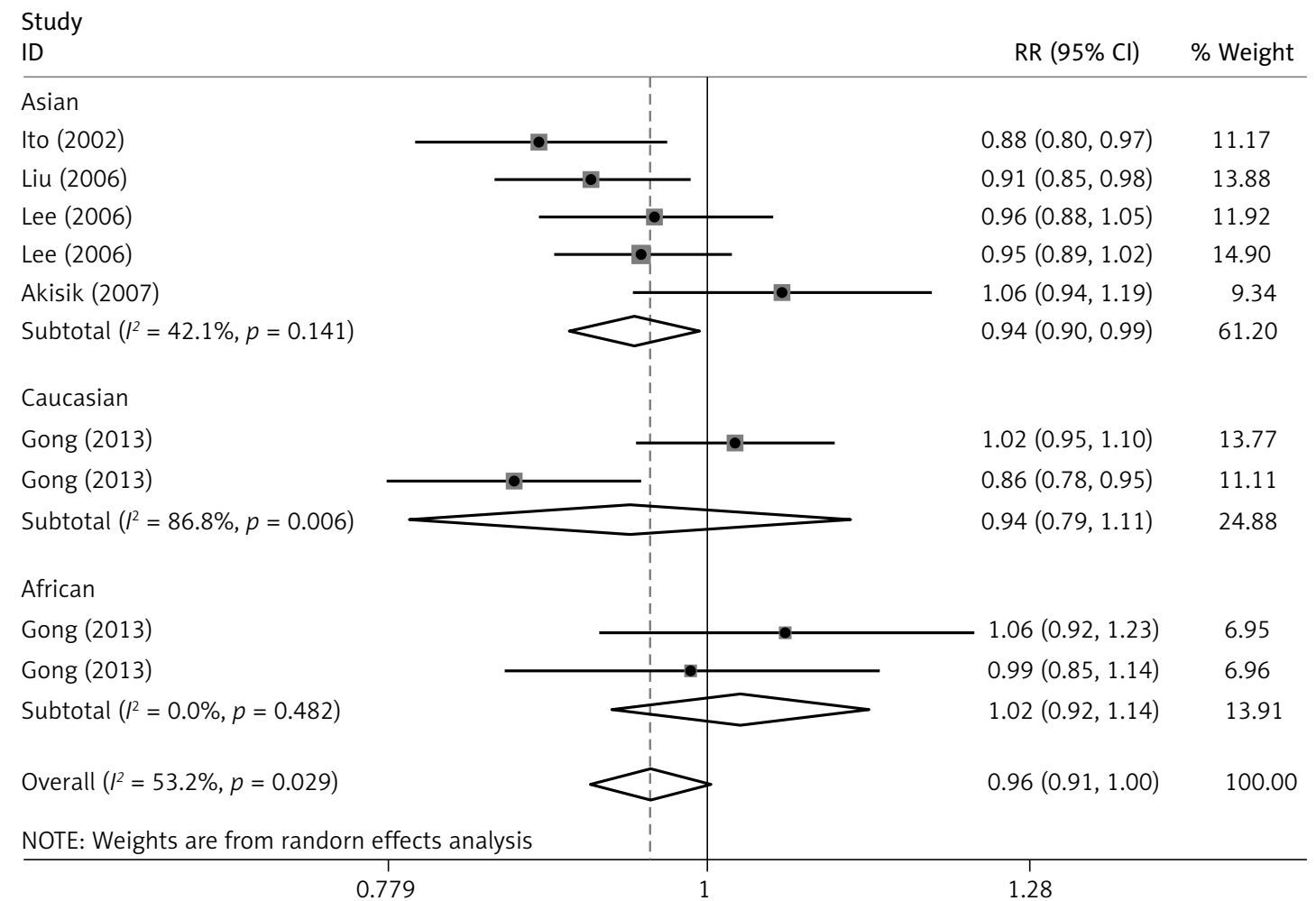

Figure 3. OR of breast cancer in different ethnicities associated with rs1143627 in IL-1 $\beta$ gene for the CT + TT genotype compared with the CC genotype

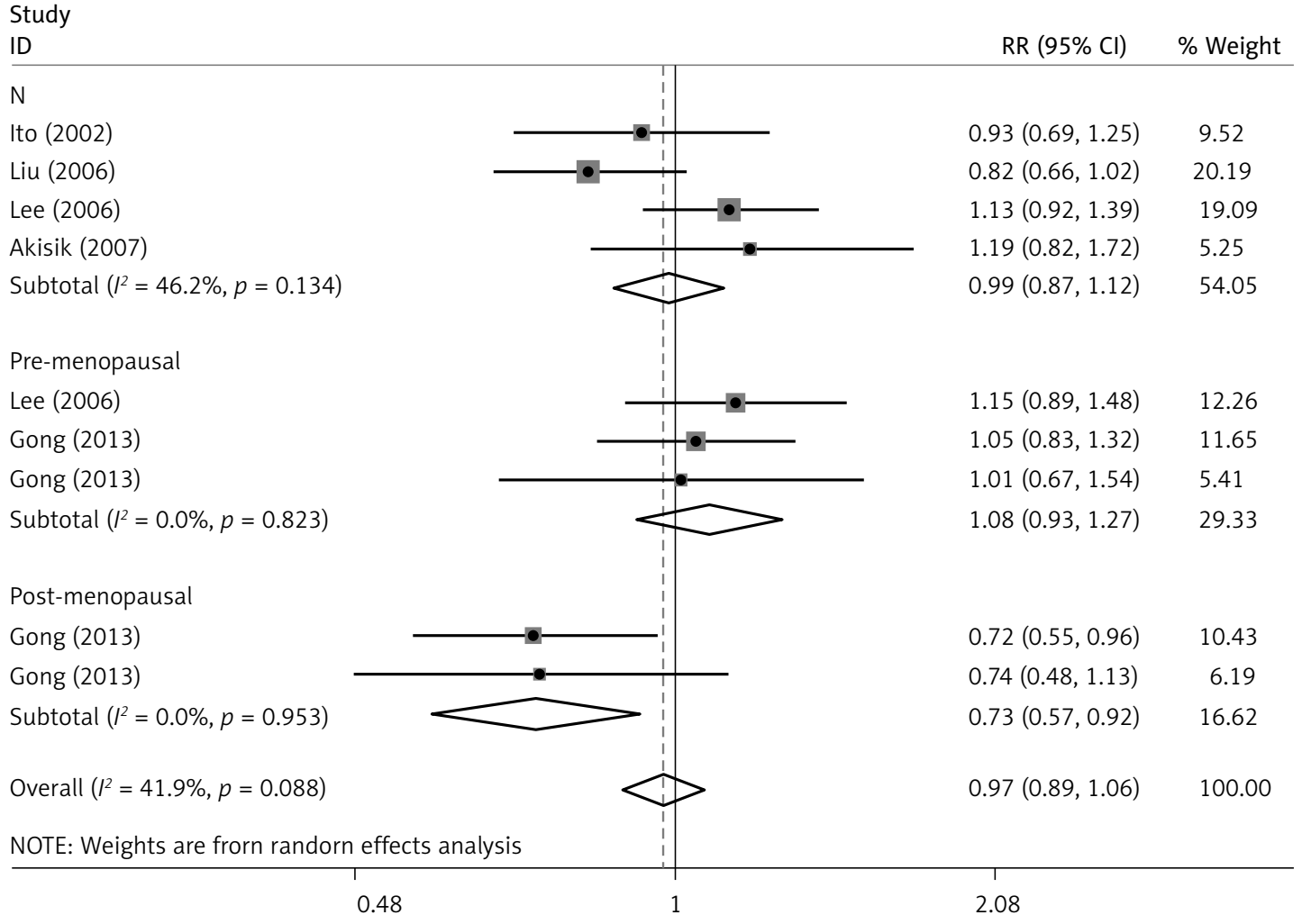

Figure 4. OR of breast cancer in different menopausal state associated with rs1143627 in IL-1 $\beta$ gene for the TT genotype compared with the CC + CT genotype 
A

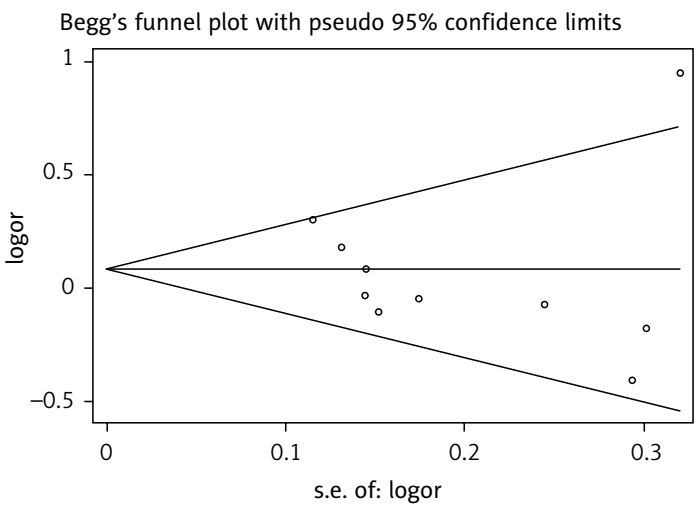

C

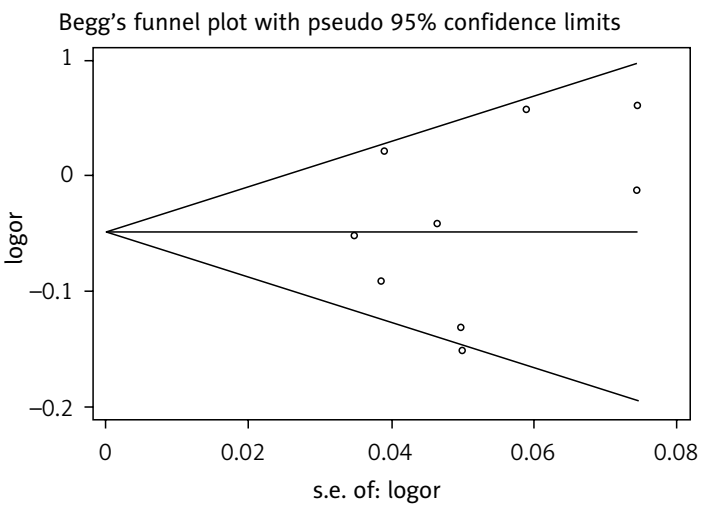

B

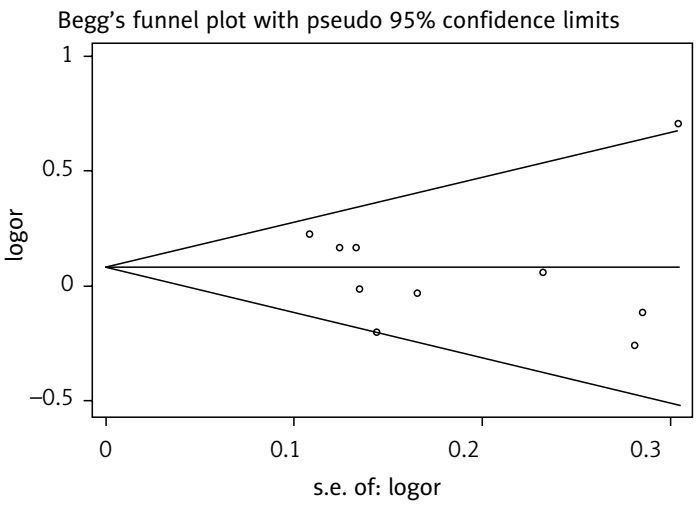

D

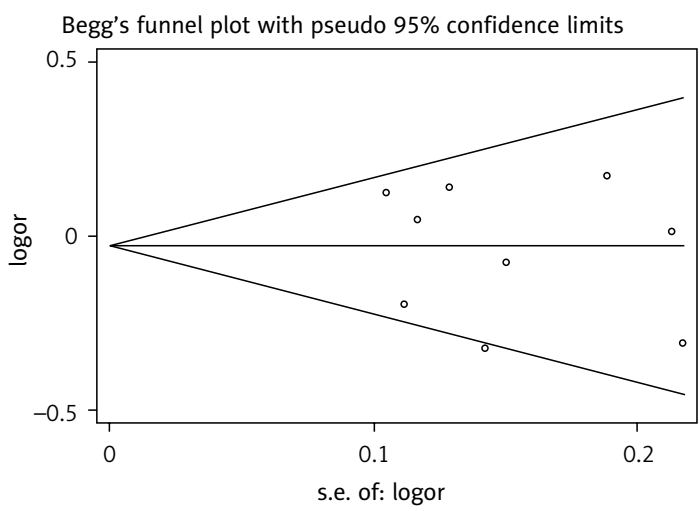

Figure 5. Begg's funnel plot analysis of publication bias. A - rs16944 in TT vs. CC + CT model. B - rs16944 in TT vs. CT model. C - rs1143627 in CT + TT vs. CC model. D - rs1143627 in TT vs. CC + CT model

associated with breast cancer risk in all genetic models. To go a step further, the data were stratified into different subgroups according to ethnicity, menopausal state, source of controls and genotyping methods. In terms of analysis by ethnic subgroup, TT genotype of rs16944 polymorphism represented a higher risk of breast cancer compared to CT genotype and CC + TT genotype and this was only significant in Asian people (TT vs. CC + CT: 1.229, 95\% Cl: 1.063-1.422, $p=0.005$, Figure 1; TT vs. CT: $1.211,95 \% \mathrm{Cl}: 1.057-1.388$, $p=0.006$, Figure 2), not in Caucasian and African populations. Similarly, it is only in Asian people that a significantly decreased breast cancer risk was found in the dominant model (CT + TT vs. CC: $O R=0.944,95 \% \mathrm{Cl}: 0.897-0.994, p=0.027$, Figure 3) for the rs1143627 polymorphism. With patients being stratified according to the menopausal state, we noted that the rs1143627 polymorphism correlated with reduced breast cancer risk among post-menopausal women in three genotype models: the allele model (T vs. C: 0.859 , 95\% Cl: $0.753-0.98, p=0.024)$, the recessive model (TT vs. CC + CT: $0.727,95 \%$ Cl: 0.576-0.918, $p=0.007$, Figure 4), and the homozygous model (TT vs. CC: $0.743,95 \% \mathrm{Cl}: 0.626-0.882, p=0.001$ ).
No significant associations between IL-1 $\beta$ polymorphism and breast cancer risk were found in other stratified analyses based on source of controls and genotyping methods.

\section{Publication bias}

Egger's test and Begg's funnel plot were used so that we could evaluate the potential publication bias of the studied literature. No obvious evidence of publication bias was detected in IL-1 $\beta$ (rs16944, rs1143634, rs1143627) (Figure 5). Also, good results were obtained in the sensitivity analysis (Figure 6).

\section{Discussion}

It is believed that cytokines are strongly connected to cancer pathogenesis accompanying increasing evidence, which suggests that they participate in tumor initiation, growth and metastasis [2]. Numerous studies about cytokine gene polymorphisms have been conducted to investigate their relations with many inflammatory and neoplastic diseases [14]. Emerging studies have reported the associations between IL-1 $\beta$ polymorphisms and breast cancer risk because of IL-1 $\beta$ 's 


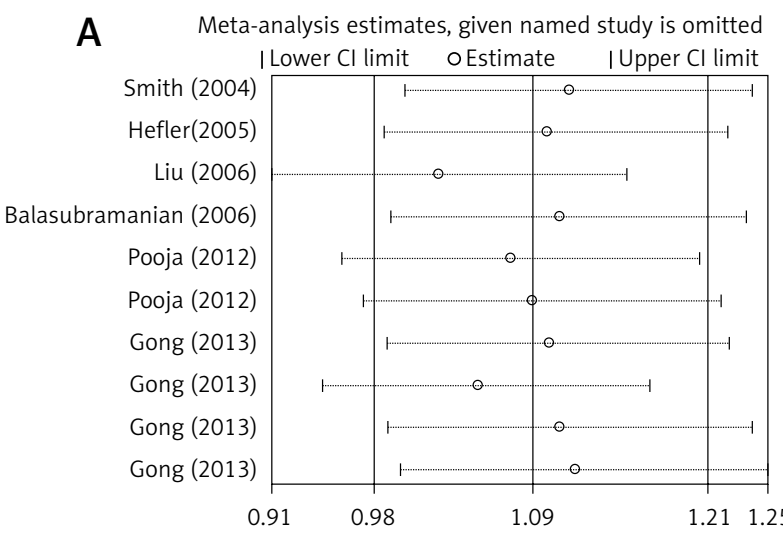

B Meta-analysis estimates, given named study is omitted

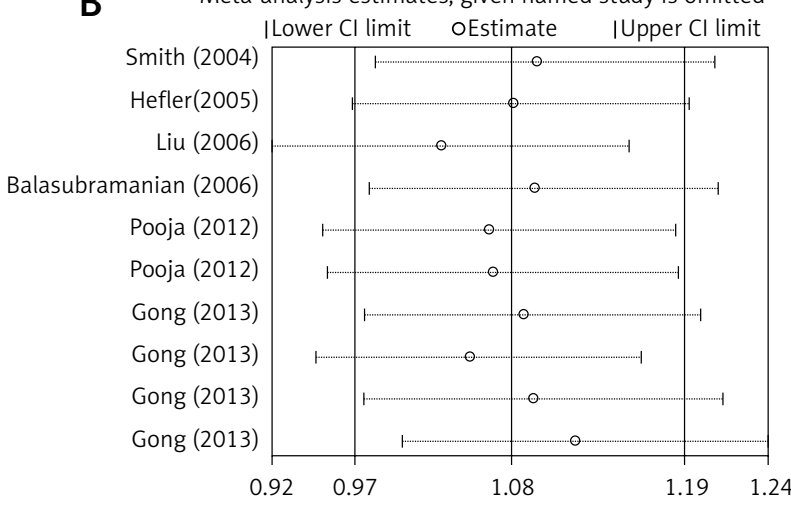

C

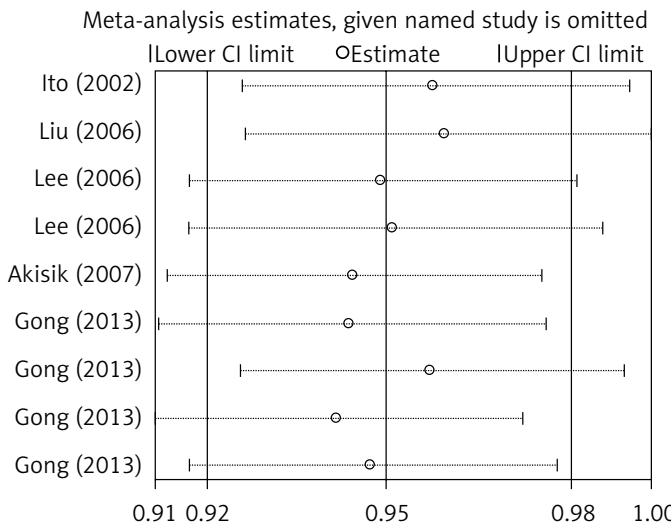

D

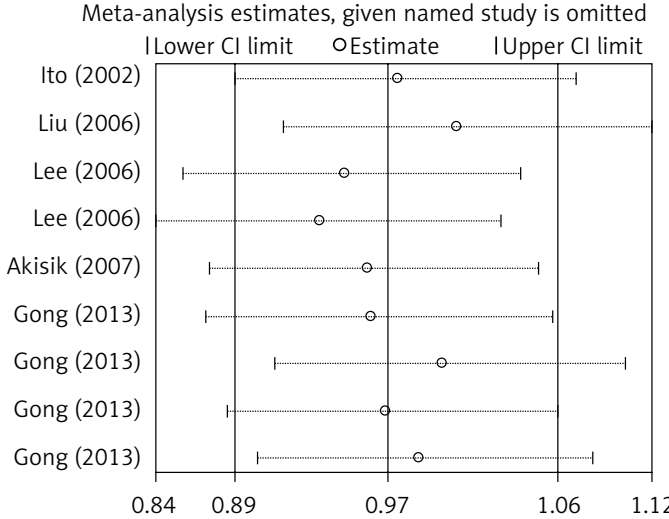

Figure 6. Sensitivity analysis. A - rs16944 in TT vs. CC + CT model. B - rs16944 in TT vs. CT model. C - rs1143627 in CT + TT vs. CC model. D - rs1143627 in TT vs. CC + CT model crucial importance in breast cancer development. The size of samples in a single study was relatively small and the controls of some studies deviated from HWE, so the results were controversial. For example, Ito et al. first reported that rs 1143627 was significantly associated with breast cancer risk [10] and another case-control study by Liu et al. verified this conclusion in the Chinese population [16]. However, Lee et al. and Akisik and Dalay did not find significant differences [15, 17]. Studies by Snoussi et al. and Pooja et al. revealed highly significant associations between rs 1143634 and the aggressive phenotype of breast cancer [13, 18]. On the other hand, Hefler et al. and Balasubramanian et al. did not find significant differences $[12,14]$. For rs 16944 , some studies indicated that rs16944 genotype reduced the risk of breast cancer, while others showed the opposite results.

Liu et al. conducted a meta-analysis to investigate the relations between three polymorphisms in IL-1 $\beta$ gene and the risk of breast cancer [25]. The variant genotype of rs 1143627 was found to be associated with a significantly increased breast cancer risk while the polymorphisms rs16944 and rs1143634 did not represent any associations with breast cancer risk, which was inconsistent with our results. As Wang et al. mentioned [26], the data reported by Liu et al. conflicted with the data from some previous publications, so the results provided by Liu et al. were untrustworthy. Given this situation, we conducted an updated meta-analysis to investigate the associations between three polymorphisms in the IL-1 $\beta$ gene and breast cancer risk.

Some potential limitations in the present metaanalysis should be taken into consideration. First of all, compared to the one included in previous studies, this sample size was larger, but it was still relatively small for some SNPs and stratified analyses. Next, we could not conduct haplotype analysis and linkage disequilibrium, because more details about personal information regarding genotypes of the SNPs (rs16944, rs1143634 and rs1143627) in IL-1 $\beta$ gene were unavailable. Furthermore, it is difficult for us to evaluate potential interactions between gene-environment, gene-gene and multiple polymorphic loci in the same gene. Regardless of these limitations, our present meta-analysis includes a much larger number of eligible studies and a stratified analysis.

In conclusion, our current meta-analysis suggests that the rs 16944 polymorphism is significantly associated with increased risk of breast cancer among the Asian population, while the rs1143627 polymorphism reduces the breast cancer risk in post-menopausal women. In the future, we need further large-scale and rigorous studies to validate these findings. 


\section{Acknowledgments}

We give thanks to Mrs Dandan Chen for providing language help.

This work was supported by the National Natural Science Foundation of China (No.31801171), China Postdoctoral Science Foundation (No. 2019M650102), Wuxi Commission of Health and Family Planning (No. Q201829) and Top Talent Support Program for young and middle-aged people of Wuxi Health Committee (No. HB2020039).

\section{Conflict of interest}

The authors declare no conflict of interest.

\section{References}

1. Rannala B. Finding genes influencing susceptibility to complex diseases in the post-genome era. Am J Pharmacogenomics 2001; 1: 203-21.

2. Smyth MJ, Cretney E, Kershaw MH, Hayakawa Y. Cytokines in cancer immunity and immunotherapy. Immunol Rev 2004; 202: 275-93.

3. Malinowski D, Paradowska-Gorycka A, Safranow K, Pawlik A. Interleukin-21 gene polymorphism rs2221903 is associated with disease activity in patients with rheumatoid arthritis. Arch Med Sci 2017; 13: 1142-7.

4. Kolovou V, Bilianou H, Giannakopoulou V, et al. Five gene variants in nonagenarians, centenarians and average individuals. Arch Med Sci 2017; 13: 1130-41.

5. Bensen JT, Dawson PA, Mychaleckyj JC, Bowden DW. Identification of a novel human cytokine gene in the interleukin gene cluster on chromosome 2q12-14. J Interferon Cytokine Res 2001; 21: 899-904.

6. Dinarello CA. Biologic basis for interleukin-1 in disease. Blood 1996; 87: 2095-147.

7. Dinarello CA. The interleukin-1 family: 10 years of discovery. FASEB J 1994; 8: 1314-25.

8. Momiyama Y, Hirano R, Taniguchi H, Nakamura H, Ohsuzu F. Effects of interleukin-1 gene polymorphisms on the development of coronary artery disease associated with Chlamydia pneumoniae infection. J Am Coll Cardiol 2001; 38: 712-7.

9. Eklund C, Jahan F, Pessi T, Lehtimaki T, Hurme M. Interleukin $1 \mathrm{~B}$ gene polymorphism is associated with baseline C-reactive protein levels in healthy individuals. Eur Cytokine Netw 2003; 14: 168-71.

10. Ito LS, Iwata H, Hamajima N, et al. Significant reduction in breast cancer risk for Japanese women with interleukin 1B -31 CT/TT relative to CC genotype. Jpn J Clin Oncol 2002; 32: 398-402.

11. Smith KC, Bateman AC, Fussell HM, Howell WM. Cytokine gene polymorphisms and breast cancer susceptibility and prognosis. Eur I Immunogenet 2004; 31: 167-73.

12. Hefler LA, Grimm C, Lantzsch T, et al. Interleukin-1 and interleukin-6 gene polymorphisms and the risk of breast cancer in caucasian women. Clin Cancer Res 2005; 11 5718-21.

13. Snoussi K, Strosberg AD, Bouaouina N, Ben Ahmed S, Chouchane L. Genetic variation in pro-inflammatory cytokines (interleukin-1beta, interleukin-1alpha and interleukin-6) associated with the aggressive forms, survival, and relapse prediction of breast carcinoma. Eur Cytokine Netw 2005; 16: 253-60.
14. Balasubramanian SP, Azmy IA, Higham SE, et al. Interleukin gene polymorphisms and breast cancer: a case control study and systematic literature review. BMC Cancer 2006; 6: 188.

15. Lee KM, Park SK, Hamajima N, et al. Genetic polymorphisms of interleukin-1 beta (IL-1B) and IL-1 receptor antagonist (IL-1RN) and breast cancer risk in Korean women. Breast Cancer Res Treat 2006; 96: 197-202.

16. Liu J, Zhai X, Jin G, et al. Functional variants in the promoter of interleukin-1beta are associated with an increased risk of breast cancer: a case-control analysis in a Chinese population. Int J Cancer 2006; 118: 2554-8.

17. Akisik E, Dalay N. Functional polymorphism of thymidylate synthase, but not of the COMT and IL-1B genes, is associated with breast cancer. J Clin Lab Anal 2007; 21: $97-102$

18. Pooja S, Chaudhary P, Nayak LV, et al. Polymorphic variations in IL-1beta, IL-6 and IL-10 genes, their circulating serum levels and breast cancer risk in Indian women. Cytokine 2012; 60: 122-8.

19. Gong Z, Quan L, Yao S, et al. Innate immunity pathways and breast cancer Risk in African American and European-American women in the Women's Circle of Health Study (WCHS). PLoS One 2013; 8: e72619.

20. X, Li M, Yang Y, et al. Interleukin gene polymorphisms in Chinese Han population with breast cancer, a case-control study. Oncotarget 2018; 9: 17994-8001.

21. Xu LB, Zhou YF, Yao JL, et al. Apolipoprotein A1 polymorphisms and risk of coronary artery disease: a metaanalysis. Arch Med Sci 2017; 13: 813-9.

22. Wang Z, Fu Y, Tang C, Lu S, Chu WM. SULT1A1 R213H polymorphism and breast cancer risk: a meta-analysis based on 8,454 cases and 11,800 controls. Breast Cancer Res Treat 2010; 122: 193-8.

23. Cao Y, Wang X, Cao Z, Wu C, Wu D, Cheng X. Genetic polymorphisms of MBL2 and tuberculosis susceptibility: a meta-analysis of 22 case-control studies. Arch Med Sci 2018; 14: 1212-32.

24. Zhai C, Li S, Feng W, et al. Association of interleukin-17a rs2275913 gene polymorphism and asthma risk: a metaanalysis. Arch Med Sci 2018; 14: 1204-11.

25. Liu X, Wang Z, Yu J, Lei G, Wang S. Three polymorphisms in interleukin-1beta gene and risk for breast cancer: a meta-analysis. Breast Cancer Res Treat 2010; 124 821-5.

26. Wang $\mathrm{Y}$, Chu X, Wang $\mathrm{H}$. Note of clarification regarding data on the association between the interleukin-1beta $-511 \mathrm{C}>\mathrm{T}$ polymorphism and breast cancer risk. Breast Cancer Res Treat 2016; 155: 419-21. 